\title{
Effects of Geometric Stress Concentration in the Design of Thick Compound Cylinders- A Review
}

\author{
Naftali Kiplagat*, Leonard Masu ${ }^{1}$, and Patrick Nziu ${ }^{2}$ \\ Department of Mechanical Engineering \\ Vaal University of Technology, Vanderbijlpark Campus, Private Bag X021, Vanderbijlpark-1911, Andries Potgieter Blvd, South Africa.
}

ORCIDs: 0000-0003-1203-645X (Naftali Kiplagat), 0000-0002-8544-6321 (Prof. LM Masu), 0000-0002-5899-0700 (PK Nziu)

\begin{abstract}
This paper reviews some of the critical considerations that are important during the design of high-pressure vessels. These critical considerations include Stress Concentration Factors (SCF), measurement of stress distribution, and geometric design parameters affecting stress concentration in the design of pressure vessels with a specific focus on thick compound cylinders. Further, the motivation of this study is to analyze stress concentration that occurs after the provision of cross bores in pressure vessels. Stress analysis can be performed using experimental, analytical, and numerical techniques. Hence, the study concluded that there is no known analysis carried out on the effects of cross bores on thick compound cylinders using Finite Element Analysis (FEA). Thus, there is need for understanding the effects of optimization of geometric parameters of cross bore size, shape, location, obliquity and thickness ratio, in the design of thick compound cylinders.
\end{abstract}

Keywords: Stress concentration, Stress Distribution, Stress Concentration Factors, High-Pressure Vessels, Thick Compound cylinders, Finite Element Analysis.

\section{INTRODUCTION}

Pressure vessels can be used in nuclear plants, thermal power plants, chemical industries as well as process industries, space depths, and supply of fluids in industries (Kharat and Kulkarni, 2013). Besides, pressure vessels are often equipped with openings so that nozzles, handholds, and manholes can be accommodated. These holes vary in size and can range from big openings having flanges to small drain nozzles. These holes are often referred to as cross bore(Makulsawatudom et al., 2004). The cross bore is a critical catalyst of a flaw in a pressure vessel because of the high-stress concentrations that arise in the presence of the cross bore (Masu and Craggs, 1992). Consequently, the cross bore will cause geometric discontinuities that alter stress distribution and create regions that are called areas of stress concentrations. Thus, the geometrical configuration severely affects the high-stress concentration of the cross bore where it intersects with the main bore. The stress concentration due to static stresses is determined using a factor that is known as the Stress Concentration Factor (SCF)(Nziu and Masu, 2019a).

\section{MEASUREMENT OF STRESS DISTRIBUTION}

Stress analysis of important elements that are subjected to various loading conditions has been conducted by researchers for the safe design of the element. Therefore, the analysis of stress distribution in pressure vessels can be determined through experimental, analytical, or numerical techniques. Experimental techniques obtain results directly (Kharat and Kulkarni, 2013) while stresses distribution in a structure having boundary conditions which are dislodgments and/or forces on the boundary can be evaluated by either analytical or numerical technique(Dharmin et al., 2012).

Experimental methods use various techniques like a grid, coating moiré, photoelasticity, grid, brittle, electrical strain gauge measurements, and other experimental solutions. Electrical strain gauges are the most deployed and acceptable for strain measurement and stress analysis (Nagpal et al., 2012) In the experimental method, prototype is largely used for experimental testing, however, pressure vessel prototype analysis is relatively expensive and consumes time (Masu, 1998).

Analytical techniques also are known as closed-form analytical methods that solve boundary value problems analytically using equations constituted based on the plastic or elastic behavior of the material subjected to forces (Dharmin et al., 2012). Analytical solutions can also be obtained from simple geometry (Nagpal et al., 2012) and, using various mathematical methods such as complex function theory, such as complex variable approach, Laurent series expansion, conformal mapping, boundary application, etc. and some integral transforms like Laplace, Mellin, Fourier, Hanckel, Eigenfunction expansion, etc.. Over time, computer software packages like Maple and Matlab have been used to answer the simultaneous equations generated by these analytical techniques.

Finally, numerical techniques obtain approximate solutions for boundary-value problems by the adoption of numerical methods like finite difference technique, finite element method, finite volume method, boundary element method, and meshless method(Nagpal et al., 2012). Each of these techniques is deployed for various applications. Hence, to solve discontinuous or moving boundaries problems, Mesh Free method has been used (Dharmin et al., 2012) while the Boundary Element Method has been deployed for modeling problems with rapidly changing stresses. The Finite Element Method has been deployed by many researchers to compare the 
analytical and experimental results and therefore the method can be used for simulation (Kharat and Kulkarni, 2013).

In the finite element method, elements that are small pieces having simple shapes are obtained from the structural model to be analyzed. Using Finite Element Analysis (FEA) the program develops an equation that governs the behavior of each element while considering the connectivity of the elements to other elements by nodes. Therefore, these developed equations are used to relate the unknown items like displacements in stress analysis, to the known material properties, loads, and restraints. The package goes ahead and constitutes equations into a large set of simultaneous algebraic equations into their thousands and also to their millions. The program solves the simultaneous equations to obtain the stress distribution for the whole model. Recently, with the introduction of computer software programming, advanced software based on the FEA theory has been developed. This software includes COSMOL, ADINA, NASTRAN, ABAQUS, LUSAS, etc, which have been commonly used in performing stress analysis. Researchers and designers deploy software depending on the type of stress analysis, the type of elements to be analyzed, and the amount of accuracy necessary. However, there is very common software that is used and is indicated in table 1. Therefore, numerical methods have become preferable over experimental and analytical methods because of the speed and convenience of use with results being accurate enough to become acceptable (Zhang et al., 2012).

However, to achieve accuracy in generating accurate numerical solutions during modeling some factors have to be considered. These factors include boundary conditions, material, domain, and material (Qadir and Redekop, 2009). It is also important to note that FEA analysis can be done using only a small portion possibly a quarter or an eighth of the whole cross-section in symmetrical structures (Masu, 1991) This method helps in reducing the amount of memory that will be needed from the computer memory required and as well as decreasing the run time of the analysis by approximately $75 \%$ (Kihiu and Masu, 1995).

In summary, analysis of stress distribution in high-pressure vessels can be determined by experimental, analytical, or numerical techniques.

Table 1: Applications of some of the common FEA software used in stress analysis (Nziu, 2018)

\begin{tabular}{|l|l|l|l|}
\hline S/No. & $\begin{array}{l}\text { Name of the } \\
\text { software }\end{array}$ & General area of preferred applications & Capabilities \\
\hline 1. & ANSYS & $\begin{array}{l}\text { Structural, electrical, civil, and mechanical } \\
\text { engineering. }\end{array}$ & $\begin{array}{l}\text { Stress analysis, heat transfer, fluid flow, and } \\
\text { electromagnetic. }\end{array}$ \\
\hline 2. & COSMOL & $\begin{array}{l}\text { Nuclear, electrical, civil, and electrical engineering. } \\
\text { Stress analysis, electromagnetic, heat } \\
\text { transfer, and fluid flow. }\end{array}$ \\
\hline 3. & DYNA & $\begin{array}{l}\text { Automobile, aerospace, civil and biomedical } \\
\text { engineering. }\end{array}$ & $\begin{array}{l}\text { Impact, vibration, stress analysis, and fluid } \\
\text { flow. }\end{array}$ \\
\hline 4. & ABAQUS & $\begin{array}{l}\text { Aerospace, automotive, electrical, hydraulic, } \\
\text { mechanical, structural, and biomedical engineering. }\end{array}$ & $\begin{array}{l}\text { Stress analysis, buckling, vibration, impacts, } \\
\text { heat transfer, fluid flow, and electromagnetic. }\end{array}$ \\
\hline 5. & PAFEC 75 & $\begin{array}{l}\text { Structural, automotive, and mechanical engineering. } \\
\text { Stress analysis, impact, vibration, and } \\
\text { buckling. }\end{array}$ \\
\hline 6. & ADINA & $\begin{array}{l}\text { Electrical, mechanical, and structural engineering. } \\
\text { Structural, heat transfer, fluids flow, and } \\
\text { electromagnetic. }\end{array}$ \\
\hline 7. & NASTRAN & Automotive, mechanical and structural engineering. & Vibration, impact, and stress analysis. \\
\hline 8. & LUSAS & $\begin{array}{l}\text { Aerospace, civil, mechanical, and structural } \\
\text { engineering. }\end{array}$ & $\begin{array}{l}\text { Stress analysis, fluid flow, buckling, and } \\
\text { vibration. }\end{array}$ \\
\hline
\end{tabular}

\section{STRESS CONCENTRATION FACTOR (SCF)}

The intensity of stress concentration is initiated by an abrupt change of section can be expressed as a Stress Concentration Factor. Therefore, SCF is calculated by the relationship given in eq. 3.1 and eq.3.2, and it includes theory in the engineering of maximum stress/strain and nominal stress. SCF is defined as the relationship between the actual maximum stress $\sigma_{\max }$ with the nominal value $\sigma_{\text {nom }}($ Hearn, 1997). Therefore in general, two forms of SCF are used in calculating the magnitude of the SCF; (i) theoretical and (ii) actual. Theoretical form of calculating the magnitude of SCF has been described in the literature (Masu, 1998; Hearn, 1999) and is shown in eq. 3.1.

$$
\text { Theoretical SCF }=\frac{\text { Maximum stress at a point due to presence of discontinuity }}{\text { Corresponding stress at the same point without discontinuity }}
$$

While Eq. 2.2 describes the actual form of SCF (also known as nominal) used to calculate its magnitude. 


$$
\text { Actual SCF }=\frac{\text { Maximum stress }}{\text { Nominal stress }}=\frac{\sigma_{\max }}{\sigma_{\text {nom }}}
$$

Subsequently, it is been shown in the literature that maximum stress does not necessarily arise at the connection of the cross bore and the main bore, however, it occurs some distance away from the cross bore intersection (Nziu and Masu, 2019b). This is because the working stresses at the nominal area (at the intersection) increase rapidly until they reach the yield point. Eventually, the material deforms permanently at these points (local yielding) resulting in a reduction of working stresses. With the earlier description of theoretical SCF, where you consider the stress as a point of discontinuity, theoretical SCF is therefore favored in the design of cross bored pressure vessels. Further, theoretical SCF represents the intensity of stress concentration at each particular point of interest (Ford and Alexander, 1997).

Stress concentration is caused by the presence of any form of discontinuity in a structure. A discontinuity can either be in the inform of load, metallurgical, geometrical, or a combination thereof, alter the otherwise uniform stress distribution across the structure (Nziu and Masu, 2019a). This alteration of uniform stress distribution leads to the creation of high-stress concentration particularly in the neighborhood regions of the discontinuity (Cole et al., 1976).

Stress concentration is measured using different types of dimensionless factors. The classification of these types of dimensionless factors varies with the type of discontinuity and the working conditions of the structure, among other considerations (Nziu and Masu, 2019b). For geometrical discontinuity, such as holes, cavities, notches, fillets, and grooves, this stress factor is referred to as Stress Concentration Factor (SCF) (Ford and Alexander, 1977). Besides, high magnitudes of SCF have been linked to the cause of most failures in structural engineering design such as fatigue, fracture, and premature yielding (Nziu and Masu, 2019c). As a result, SCF remains one of the important parameters to be determined in any engineering design (Kihiu, 2002).

The stress concentration factors caused by the hole can be expressed in various ways depending on the service condition of the vessel or different design applications. Hence, SCFs can be well defined using maximum considered stress, and not necessarily the stress at the junction between the cross hole and the main bore (Çömlekçi et al., 2007). Therefore, three different types of SCFs can be considered namely maximum principal stress SCFs, Tresca yield criterion stress intensity (SI), and Von Mises yield criterion equivalent stress. The maximum principal stress SCF is the calculated value of stress at the inner surface of a similar plain cylinder (based on maximum tensile stress or hoop stress arising from the hole). This stress concentration factor can be also be called the hoop SCF and is applied in design analysis concerning fracture and fatigue analysis. On the other hand, the Von Mises equivalent SCF is appropriate to fatigue analysis and multi-axial yield load that is based on the Von Mises criterion. This SCF is expressed as a function of the maximum value of the Von Mises equivalent stress in the pressure vessel as well as the equivalent stress value at the inner surface of the same plain cylinder derived after the Lame's solution. Finally, the Tresca equivalent stress or Stress Intensity (SI) stress concentration factor is appropriate in calculating fatigue and yield load for design applications in vessels following the Tresca criterion (maximum shear stress). This stress concentration factor is also known as shear SCF is defined according to the maximum value of the Tresca stress intensity in the pressure vessel that has a cross hole and the value of the inner surface of an equivalent plain cylinder derived from the Lame's equation. These Von Mises and Tresca's SCFs enable a comparison between working stresses in cylinders with different sizes subjected to varying loading magnitudes (Nziu, 2018). It has been reported that for pressurized cross bore cylinders maximum stress does not occur at the intersection between the cross hole and the main bore but slightly somewhere up the cross hole from the junction with the main bore (Çömlekçi et al., 2007; Masu, 1989). Therefore, theoretical SCF or maximum principal stress SCF is preferred in a cross bore cylinders since maximum hoop stress does not essentially happen at the intersection.

The problem of stress concentration at cross bores of cylinders under internal pressure has become a concern to the highpressure industry. Additionally, stress concentration factor is linked to persistent difficulties met during the design of pressure vessels such as local yielding, fatigue failures, and fractures (Nziu, 2018). As a result, solving the problem has become a concern to researchers. The earliest research on stress concentration was on stress distribution in a tee intersection of thick cylindrical pipes (Fessler and Lewin, 1956). The researchers developed an estimated technique of analysis and the results were compared with data generated during experiments of stresses in a junction created from Araldite casting-resin B by the frozen photo-elastic model. This model consisted of a cylinder of thickness ratio of $\mathrm{K}=3$ and bore ratio of $K_{s}=2$ where,

$$
\text { Thickness Ratio, } K=\frac{\text { outside diameter }}{\text { bore diameter }}
$$

Bore ratio, $K_{s}=\frac{\text { Bore diameter }}{\text { Sidehole diameter }}$

The SCF results gave a theoretical value of 3.70 that was more than the measured value of 2.80 indicating a $32 \%$ difference.

The stress projected by the concept advanced by Fessler and Lewin (1956) gave results that were too big. Nevertheless, their model introduced the equations that were used to analyze asymptotic SCFs for cylinders with side holes ratio of $\mathrm{K}_{\mathrm{s}}=2$ which was sufficiently small as compared to the bore. 
More extensive research was on the consequence of introducing either elliptic or circular side holes to cylinders then exposed to internal pressure (Faupel and Harris, 1957). The researchers used two well-known experimental techniques of strain gauges as well as photoelasticity and compared them with the theoretical analysis. Their results were reasonably in agreement however their data revealed the predictions not being perfect, but generally acceptable from an engineering perspective. Faupel and Harris (1957) projected a general stress concentration value of $K_{h}=2.5$ for closed-end cylinders that have small side holes and they went ahead to suggest that more work remains to be done. However, an error was pointed out in the theoretical framework of Faupel and Harris (Morrison et al., 1959). The method consisted of superimposing the entire system to fictitious volumetric tension which facilitated determining consequently the hoop SCF of small circular crossbore which was found to be 2.5. Morrison et al (1959) provided both analytical and experimental solutions and suggested a simple manner of calculating the hoop stress concentration factor. The authors suggested the fictitious volumetric tension be removed and replaced with a hoop SCF shown in equation 3.5 ,

$$
\text { Stress concentration factor }=\frac{4 K+1}{K^{2}+1}
$$

$K=$ the ratio of external to the internal diameter of the cylinder.

The amount of the difference changes with $K$ that is for a very thin cylinder the error is small while for a thick cylinder, $K=2$ is $36 \%$.

Research on the inquiry into the benefits that could arise from the usage of an oblique, or circular section that has been offset axis for a hole, or from an elliptical cross-section was done on high-pressure containers (Cole, 1969). This was the first study on the consequence of offset branch holes in a pressure vessel. Cole (1969) started by stating that it was important to note that, independent of the value of the ratio of bore diameter to outer diameter for a vessel, a cross bore can introduce shear stress that is two and half times the calculated value found in a plain cylinder. This, therefore, implies that the introduction of cross bore instantly reduces the safe working pressure of a cylinder by over $40 \%$. Consequently, Cole (1969) proved that by making a cross-bore to be elliptical with its axis and coincident with the radial line or by using circular cross bores that are offset from the centerline of a cylinder, showed that stress concentration can be minimized. Hence, by comparing cylinders that are produced from Tresca-type and Von Mises material theoretically, and having either an elliptical radial cross-bore that is optimally or a circular cross-bore in a central position in an optimally offset location, the evaluation was performed. For a Tresca material, the ratio of safe working pressures of a plain cylinder to circular ross-bore at the radial position to elliptical cross bore at the radial position was 1:0.4:0.667. Therefore, from the above ratio, the elliptical section gave $67 \%$ more allowable pressure than the corresponding circular section. Von Mises material gave consistent results of the working pressure of optimum elliptical hole being almost $67 \%$ more than that of a diametral circular hole and the best oblique round hole being $60 \%$ more than that of a diametral circular hole. The research work by Cole (1979) was later proven experimentally by performing fatigue tests on cylinders having circular cross-sections at various offset positions with thickness ratios of $\mathrm{K}=1.4$ as well as $\mathrm{K}=1.8$ (Cole et al., 1976). The conclusion stated that fatigue tests showed that for a thick cylinder having a small cross bore, its fatigue life of the cylinder increased if the cross-bore is slightly offset away from the radial center-line of the cylinder. Besides, it was shown that the fatigue life of a cylinder having a cross bore that is optimally positioned is more than one that has a radial crossbore by roughly $100 \%$ for a cylinder with $\mathrm{K}=1.8$, and by roughly $170 \%$ for a cylinder with $K=1.4$.

A more refined approximate analysis has been reported by Gerdeen (1971) study in the determination of SCFs on the hoop stress for side hole and cross-hole cylinders(Gerdeen, 1971). The side hole and cross holes were both exposed to both external and internal pressure. The analyses were performed for several geometrical configurations of the cylinder and the hole having diameter ratios of $1.5,2,3,4,5$, and 6 . The cylinder also had bore radii of the cylinder to the side hole ratio of 1.5, 2, 3, 5 , and 8, respectively. From this work, the distribution of the hoop SCF showed that the SCFs increased with the increasing cross bore size. Thus, Gerdeen (1979) showed that it is beneficial to use a small side hole ratios to reduce the SCFs from internal pressure loading. After subjecting both external and internal pressure to the cylinder and each acting separately, the theoretical results generated by Gerdeen (1979) showed that the most ideal configuration was that which the internal intersecting bores have an equal diameter. Further, results produced experimentally generated by Gerdeen and Smith (1972) confirmed the theoretical analysis earlier done by Geerdeen (1971) and agreed with the theory presented previously. The best arrangement was found to be that of a cross hole (side hole) that has a diameter that is equal to the bore diameter and having a joint radius at a tee crossing that is equal to the bore radius. The "tee" crossing of holes is required to have a radius-to-bore ratio of 0.3-04 to minimize stress concentration and the hoop SCFs for the optimum designs approach 1.4 and 1.1 for infinite side hole cylinders and crosshole cylinders, respectively.

Finite element methods started being deployed to analyze the stress fields in cross bored vessels (Chaaban and Burns, 1986). Initial attempts to the use of Finite Element analysis to calculate stress concentrations and distribution contained in cross bores gave some results (Masu, 1989; Masu and Craggs, 1992). The researchers investigated experimentally the effects of introducing chamfer or radius to in the main cylinder bore then comparing the effect with plain cross bore cylinders. The results indicated that there was no improvement of total fatigue life in the cylinders, however, these findings had to be substantiated using finite element analysis. Subsequently, the plain cross bore cylinders that have a thickness ratio of $K=2$ generated an SCF of 3.03 which compared favorably with already published data (Faupel and Harris, 1957; Gerdeen and Smith, 1972). The authors concluded that plain cross-bore cylinders having thickness ratios of $K=1.4$ as well as $K=2.0$ have a slightly more fatigue life than similar cylinders having a small blending radius or chamfer at the cross bore main bore 
connection. Another numerical study (Masu, 1997) where 3-D finite element analyses were conducted on thick-walled cylinders that are close-ended which have a cross bore that is pressurized. In this research, cylinders that have either a circular radial cross bore, a circular cross bore, and elliptical shaped radial cross bore that has been optimally offset were investigated. The effects of the cross bore diameter size on the principal stress distribution and SCFs along the plain cross bores were also studied. The outcomes showed that it was successful to decrease the hoop stress in a plain cross bore cylinder by altering the configuration or offsetting the cross bore. Hence, the authors concluded that FEA of pressure vessel stresses analysis showed that maximum hoop stresses in the circular radial cross bore cylinders to be approaching one and half times than that in radial elliptical and offset cross bores. Hence, SCF at the bore of the circular cross bore, the optimally shaped radial elliptical cross bore, and that of the optimally offset circular cross bore was 2.30,1.52, and 1.33, in that order. These results compared favorably well with other predictions of other researchers like Cole et al (1976). Further research by Masu (1998) on cylinders containing circular cross bores, at radial and offset positions from the centerline were conducted. The effects of cross-bore size at the optimum position (11.2 $\mathrm{mm}$ ) were also performed. The results showed a dependence on stress distributions as well as the SCF on the cross bore diameter size. Indications were that if you offset the position of cross bore to $11.2 \mathrm{~mm}$ the SCF in the centered cross-bore cylinders approaches 1.73 times that of cylinders with radial cross bore.

Further work on using finite element analysis by Dixon et al (2002) was done on thick-walled square blocks and cylinders. The SCFs (hoop and shear) were analyzed and presented as a function of the ratio of cross bore radius to the cylinder radius varying from 0.01 to 0.07 for a variety of wall ratios ranging from $\mathrm{K}=1.5$ to 5 . Three diverse analysis codes were used to corroborate published data i.e. ANSYS, Pro/Mechanica, and Abaqus. The results indicated that for small wall ratios in cylinders stress concentration factors increase with an increase in radius ratios. For square blocks with wall ratio less than 2, SCFs were marginally more than those found in cylinders, however, for wall ratios greater than 2 , SCFs are almost similar. The analysis of results agreed with that of Chaaban and Burns (1986), but 5-8\% higher due to finer mesh density to precisely capture the SCFs. However, what was noted is that SCF predicted by Gerdeen shows a downward tendency that was the opposite of what the researchers' analyses predicted. A paper on the effect of the radius with blends on the SCF of cross bored holes in a thick-walled cylindrical pressure vessel (Peters, 2003) was presented. The study concluded, blend radius ratios $(\mathrm{CR} / \mathrm{HR})>1.0$ is detrimental to fatigue. However, with small blend ratios, it can reduce stress concentration up to $6 \%$ in certain cases, but may also increase the stress by up to $10 \%$. Overall large radii can lead to a wall with greatly reduced stiffness in the area of a cross bore, causing much higher stresses and reduced fatigue life. This, therefore, is in agreement with previously published data by Masu and Craggs (1992).

More work on the application of the finite element method has been performed in the of study the elastic SCFs for thick vessels that have been internally pressurized having radial and offset circular and elliptical cross holes (Makulsawatudom et al., 2004). Subsequently, plain, chamfered, and blend radius were the three types of joints between the cross hole and main bore that were considered. The study was conducted to check the effects of blending geometry on the stress field and how it influences the fatigue life of a cylinder. The authors performed the analysis on five different inner to outer radius ratios of the main cylinder where $b / a=1.5,1.75,2,2.25$ and 2.5 . Hence, two models having circular cross holes of different radii were analyzed and also two same elliptical cross holes were investigated. The analysis reinforced earlier research carried out that an elliptical profile in the intersection between the cross hole and the main bore surface reduces SCF. Also, the investigation revealed that the offset circular cross hole can be adopted to minimize the stress concentration effect but to the level of the elliptical cross hole. The results also showed when a blend radius or chamfer is introduced at the intersection between the cross hole and main bore stress increases. However, when the stress at the main bore is reduced, it leads to the introduction of higher stresses away approximately usually a distance of $1 \mathrm{~mm}$ from the cross bore intersection with the main bore. Another set of researchers (Çömlekçi et al., 2007) did an FEA investigation of stress concentration at radial cross holes in cylinders that have been subjected to pressure. The analysis considered a thick cylinder having an internal radius of $a$, and an external radius $b$, and with a length of $2 L$ and a central crosshole radius $c$. The geometry factors varied in the study were the cylinder radius ratio of $b / a$ and also a crosshole-to-bore radius ratio of $c / a$. In this investigation, the main cylinder internal radius considered was put at $a=$ $100 \mathrm{~mm}$ in all analyses. Seven thin to thick cylinder radius ratios were considered where, $b / a=1.4$, $1.5,1.6,1.75,2.0,2.25$ and 2.5. ANSYS program was used to perform finite element analysis. The analysis showed that contrary to common investigative results revealed that maximum stress occurs at the intersection between the bores, this investigation concluded that maximum stress occurs elsewhere up the cross hole from the junction (Masu, 1989). Three graphs of the stress concentration factors were plotted against the cylinder radius ratio of $b / a$ and also a crosshole-tomain-bore-radius ratio of $c / a$. The stress concentration factors were established to change across the range of geometries that were studied. Therefore optimum $b / a$ and $c / a$ ratios were able to be selected and used to give minimum stress concentration.

A computer program of analysis of three-dimensional finite element has been developed by Kihiu (2007) to be used to determine the stress distributions and SCFs in chamfered crossbored cylinders that are pressurized (Kihiu et al., 2007). It was found that optimal chamfered cylinders with a thickness ratio between 2.25 and 3 , the stress concentration factor rose with a decline in thickness ratio. Further, it was discovered that thick cylinders were more suitable to chamfering than thin cylinders. Hence a quick design tool was eventually developed out of the resulting data of the work.

A review of research on stress concentration at openings was undertaken (Kharat and Kulkarni, 2013). The paper reviewed the progress of the determining SCF at the openings of pressure cylinders. Therefore the scholars postulated that a shell that has 
no opening will achieve maximum stress compared to a shell that has a penetration. Therefore in practice, SCF has been used to compute the stress arising around the penetration or hole because the hole affected the stress distribution within the opening. The paper concluded that most researchers have used an analytical technique to understand the consequence of the diverse design parameters such as thickness, the diameter of the cylinder or shell, and the opening size. Also, the majority of researchers have used experimental methods to obtain results directly. It was clear from the study that changes in size, location, position, of openings in pressure vessels are critical elements during the study of stress concentration. Further, it was also noted that the finite element method was employed by a majority of researchers to relate analytical and experimental work.

Another review (Nziu and Masu, 2019a) of the effects of geometry configuration in a cross bore on SCFs in highpressure cylinders or vessels has been done. The paper established that studies conducted on the ideal combination of geometric design parameters of cross bore size, location, shape, obliquity, and thickness ratio, that gives minimum stress concentration in thick cylinders were non-existent. This was the case even though the magnitude of SCFs depends primarily on these critical design parameters. Therefore researchers reviewed the measurement of stress distribution and discussed the effect of geometric design parameters on SCFs in a highpressure vessel. The authors concluded that SCFs in highpressure vessels with a cross bore is influenced by geometric configuration parameters like cross bore size, shape, location, angle of obliquity, and thickness ratio. However, the researchers went on to state that the optimization of these geometric parameters has not been performed even though it is generally accepted practice to perform optimization of parameters. The paper acknowledged that there exist studies on the effect of the singular parameter on stress concentration independently but there were no existent studies if the parameter were combined. Furthermore, a study on the configuration of optimal cross bore shape in elastic pressurized high-pressure vessels has been done (Nziu and Masu, 2019b). Numerous analyses were performed to establish the optimal shape between circular and elliptical plain cross bores at radial and offset positions in a closed thick-walled cylinder. Seven cross bore cylinders having thickness ratios between 1.4 as well as 3.0 were studied. For effective comparison between circular and elliptical cross bores, the major radius of the elliptical cross bore as equal to that of circular cross bore. The behavior of hoop stresses together with that of SCFs were investigated at offset locations ranging from 0 to 0.9 using three-dimensional linear finite element analysis. Elliptical shaped cross bore predicted lower hoop stresses at the radial position than circular ones. The minimum SCF magnitude due to circular cross bore occurred at 0.9 offset position in $K=1.4$ giving a magnitude of 2.312. A magnitude of 1.733 at a thickness ratio of 2.5 was the lowest SCF magnitude produced by elliptical cross bore occurred at a radial position. This magnitude predicted by elliptical cross bore therefore doubled up as the overall optimum SCF of the study. The authors concluded that the optimal location of elliptical cross bores reduce SCF magnitudes by $33 \%$ compared to a similar circular cross bore.
From the preceding paragraphs, there is no known analysis carried out on cross bored thick compound cylinders using finite element analysis. Hence, in this current study finite element analysis will be adopted to explain this phenomenon. Further, this present study will extensively investigate the effect of geometric design parameters of cross bore size, shape, location, obliquity, and thickness ratio on stress concentration in thick compound cylinders to investigate the optimum combination.

\section{COMPOUND CYLINDERS}

With the increased shortage of raw materials and also the higher costs in the manufacture of pressure vessels, researchers have not allowed themselves to be confined to traditional elastic techniques. Researchers have however turned their consideration to the elastic-plastic techniques which offer greater efficient use of materials. Therefore, some elasticplastic techniques have been developed to increase the pressure carrying capacity of thick-walled cylinders (Majzoobi et al., 2004). These techniques involve autofrettage and the use of compound cylinders. Autofrettage is a widely adopted plastic technique developed to increase the pressure capacity of a thick-walled cylinder (Kumaresan and Chocklingam, 2018). In an autofrettage procedure, the cylinder is pressurized internally so that its wall becomes partly plastic ((Majzoobi et al., 2004). Further, the pressure is then let out leading to the development of residual stresses that leads to the increased loading capacity of the cylinder in the next pressurization stage. On the other hand, compound cylinders are formed when two or more cylinders of different diametral interferences are shrunk fit into each other. The shrinkage process generates a residual stress distribution inside the walls of the cylinders, which further changes the behavior of the cylinder against the working pressure and further increasing the pressure capacity of the cylinder (Kumaresan and Chocklingam, 2018). The stress distribution is intensely dictated by the shrinking radius, the outer radius of the inner cylinder as well as the inner radius of the outer cylinder and diametral interference or shrink fit (Majzoobi and Ghomi, 2006). Hence, if two cylinders are shrunk on one another, the inner tube comes to a state of compression as a result of the cooling of the outer tube of a cylinder conversely the outer tube will equally be brought into a state of tension. Therefore, if the compound cylinder is internal pressure is subjected to the compound cylinder, the resultant hoop stresses will be the total algebraic sum of the resulting stresses from the internal pressure and the stresses resulting from shrinkage as shown in figure 1

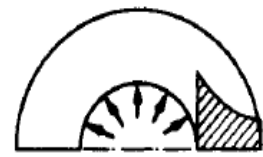
only (a) Internal pressure

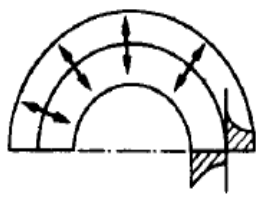

(b) Shrinkoge only

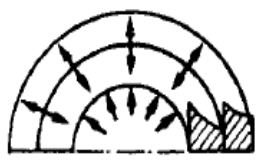

(c) Combined shrinkage and internal pressure
Figure 1. Compound cylinders- combined internal pressure and shrinkage effects (Hearn, 1997a) 
The prediction of bursting pressure in compound cylinders using experimental and finite elements has been researched by Majzoobi et al (2004). In this work, aluminum cylinders with dissimilar diametral interferences and having various shrinkage radii and a constant ratio of outer to inner radii of $K=2.2$ were exposed to autofrettage and bursting temperatures(Majzoobi et al., 2004). The researchers studied the effects of radius, diametral interference, and autofrettage in compound cylinders. A conclusion was drawn to the effect that if a single-cylinder and a compound cylinder are subjected to the same conditions, the compound cylinders having a suitable shrinkage radius performs better than the single-cylinder strengthened by autofrettage. Therefore, it was concluded that shrinking a cylinder into a compound cylinder is a more efficient technique than in increasing pressure carrying capacity than autofrettage. Further research on the optimization of compound pressure has been carried out (Majzoobi et al., 2004). The purpose of the paper was to the optimization of the weight of the compound cylinder for given pressure by changing the shrinkage radius and tolerance. Here, several closed-end cylinders having different materials, several internal pressures, and various geometries were considered. A single metal compound of steel and aluminum and a bi-metal compound cylinder of aluminumsteel were optimized. The authors concluded that compound cylinders can be lighter and cheaper to produce and can partially be deployed constructing high-pressure cylinders to minimize the weight to cost ratios of the cylinders.

As more research on the optimization of compound cylinders was carried out, the criterion of using maximum tensile stress (hoop stress) has been applied in generating the optimized design of compound cylinders (Patil, 2013). This research paper by Patil (2013), explains how to determine optimum dimensions of cylinders that are manufactured using specific material and can withstand a stated internal pressure to give a minimum volume and weight. Therefore, the compound cylinder optimization was performed for minimum weight centered on maximum tensile stress that was developed. A Three-layer compound cylinder is suitable for high operating pressures (Majumder et al., 2014). Majumder et al(2014) study that the use of compound cylinders with several layers as compared to a monoblock cylinder can lead to some savings by decreasing the weight of the compound cylinder and also the reduce the cost of the material needed in the manufacture of these multilayered compound cylinder.

An attempt to analyze the effect of SCFs on compound cylinders has been carried out (Reghunath and Sammon, 2014). In this research, cracks were introduced to single or noncompounded cylinders, compound cylinders, and autofrettaged cylinders. Both compound cylinders and single cylinders were subjected to the axial crack of $1 \mathrm{~mm}$ and stress concentration factors were obtained. After comparison, the values of the SCF value for compound cylinders were lesser than those of the single cylinder. Additionally, it was concluded that the use of autofrettage increases the pressure bearing capacity of a cylinder as it decreases the hoop and radial stress at the vicinity of the inner radius.

A model has been developed that can be employed to analyze the effects of internal pressure and temperature on the displacement fields and stress distributions in the compound cylinder (Bahoum et al., 2017) yielded interesting results. The calculations of radial movement and diverse stresses in two cylinders, inner and outer, were deduced from the cases where the cylinder is made from different or the same materials. It was concluded that the overall effects of internal pressures and temperature must be considered during the design of compound cylinders to achieve maximum efficiency and maximum accessibility.

Finally, a group of researchers performed stress analysis in compound cylinders as well as autofrettaged cylinders. Simulation of single and compound cylinders was done to understand the failure behavior, effects of autofrettage pressure, and stress levels (Kumaresan and Chocklingam, 2018). This model obtained ideal diametral interference that gave the best shrinkage radius. It was concluded that the amount of pressure compound cylinders can withstand is considerably higher than that which single-cylinder with the same geometry and material can hold. Therefore it was concluded that a compound cylinder designed with appropriate shrinkage radius, is far more superior than a similar monobloc cylinder which has been strengthened by autofrettage processes.

In conclusion, from the above review of literature on compound cylinders, it is clearly shown that most studies and research tend towards the optimization of compound cylinders based on specific parameters that affect the design of compound cylinders. The parameters include shrink radius, diametral interference, material, autofrettage, and other geometries. From the review, therefore, it is concluded that there is no information is available on the effects of cross bores in thick compound cylinders.

\section{GEOMETRIC DESIGN PARAMETERS AFFECTING STRESS CONCENTRATION IN HIGH-PRESSURE VESSELS}

When designing pressure vessels, there are basic considerations that are important (Hyder and Asif, 2008). These include acknowledgment of the expected failure modes and the stresses generated in the vessel material because of temperature and pressure. Therefore, it is paramount to select a material that can be able to withstand the effects of pressure and thermal loads as well as the effects of the environment. Finally, another basic consideration is to consider the effect of stress concentration that has been caused by geometric discontinuities, therefore, resulting in the provision of supports and openings for manholes, gauges, etc. The stated geometric discontinuities cause stress concentrations which are highly localized. Therefore, the significance of the localized stresses not only depends on its absolute value but rather on other factors. Hence, SCF depends on material physical property and the type of loading to which the pressure vessels are exposed.

In summary, the geometric design parameters that affect SCFs in pressure vessels include size, shape, location (Makulsawatudom et al., 2004), obliquity, and thickness ratio. Hence the preceding paragraphs will entail a discussion of these stated design parameters 


\subsection{Cross bore size}

To study the consequence of cross bore size on high-pressure vessels, ratios of the outside diameter to the bore diameter (eq. 2.1 ), as well as the bore diameter to the side hole diameter (eq. 2.3), are used. The relationship between stress concentration factors with different ratios of cross bore to the main bore size in pressure vessels having varying thickness ratios of 1.5, 2.0,2.5, 3.0, and 4.0 have been studied (Gerdeen, 1971). The outcomes indicate that as the ratio of cross bore to main bore cylinder increases so does the stress concentration factors. Furthermore, the results of using five different ratios of 1.5, $1.75,2,2.25$ and 2.5 also portrayed that the trend of the magnitude of SCF is dependent on the increase in a cross bore (Makulsawatudom et al., 2004). Also, an investigation on how the size of the cross bore diameter affects the principal stress distribution and the SCFs along the plain cross bores have been reported (Masu, 1997). Subsequently, the results indicated that the hoop stress distributions and the SCFs in a thick cylinder depend largely on the size of the cross bore diameter. Additionally, cylinders that are thick and have circular cross bores at the radial position were investigated (Masu, 1998). In this research, cylinders having a diameter of $25 \mathrm{~mm}$ and thickness ratio $K=2$ were examined and $0.8,1.6$, and $20 \mathrm{~mm}$ diameter hole was analyzed at an offset of $11.2 \mathrm{~mm}$ offset from the radial or centerline. It was reported that there was a dependency of stress distribution and stress concentration on cross-bore diameter size. Further experiments have concluded the best configuration of cross bores was shown to be one with a cross-hole (or side hole) diameter that is equal to the bore diameter (Gerdeen and Smith, 1972).

Three-dimensional graphs of stress concentration factors versus cylinder radius ratio and the crosshole to main bore radius ratio have been investigated (Çömlekçi et al., 2007). Here, seven thick cylinders having moderate radius ratios were considered: $1.4,1.5,1.6,1.75,2.0,2.25$, and 2.5. The cylinders also had cross-hole to bore radius ratios varying from 0.01 up to 0.25 . The investigation indicated that the maximum stress did not necessarily occur at the intersection of the cross hole and main bore as it has always been assumed in several analytical solutions.

Research optimizing the size and location of the opening in a thick cylinder by using ANSYS has been done (Hyder and Asif, 2008). In this work, three thick-walled cylindrical vessels having internal diameters of 20,25 as well as $30 \mathrm{~cm}$ and a height of $30 \mathrm{~cm}$ with a thickness of $20 \mathrm{~mm}$ were investigated. Besides, the optimization process was performed on the hole size by using holes having a diameter of $4,8,10,12,14$, and $20 \mathrm{~mm}$, and positioned at the center of each of the three different cylinders. It is reported that Von Mises stress decreases initially and then becomes constant with cross hole size. Thus, it was shown that for a cylinder having an internal diameter of $20 \mathrm{~cm}$, the optimized size is $8 \mathrm{~mm}$ while the cylinder having internal diameters of $25 \mathrm{~cm}$ and $30 \mathrm{~cm}$ with a hole size of $10 \mathrm{~mm}$ gave the lowest Von Mises stress figures.

Recently, a study to establish the cross bore size effect on the wall thickness of thick cylinders that have been conducted (Nziu and Masu, 2019c). Therefore, cylinders having thickness ratios from 3.0 down to 1.4 , and also having cross bore size ratios that range from 0.1 to 1.0 were investigated. The study showed that as the cross bore size increases the maximum hoop stress also increased. Further study by Nziu and Masu (2019d) indicated that only circular and elliptical shaped cross bores are commonly used in the design of pressure vessels. A circular cross bore is termed as being small when the ratio of the cross bore to the main bore diameter is $\leq 0.5$. Nonetheless, when the same bore ratio lies between $\geq 0.5$ and $\leq 1$ the cross bore is termed as large. On the other hand, an elliptical cross bore is described in the form of diameters ratios and their orientation with the principal stress axes. According to Nziu and Masu (2019e) study, an optimal configuration of elliptical cross bore in both thin and thick-walled cylinders has a diameter ratio of 2 when the orientation of the minor diameter is parallel to the axial direction of the cylinder.

\subsection{Cross bore shape}

Figure 2 shows an illustration of cross bore shape configuration.

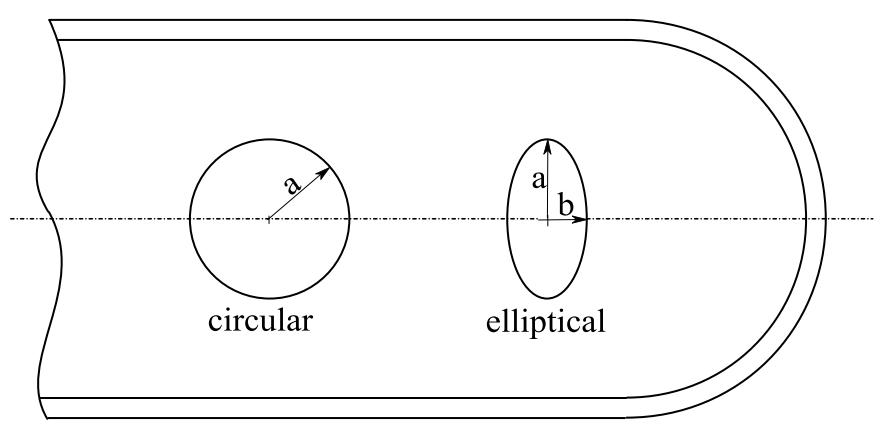

Figure 2. Cross bore shape configuration

Where $\mathrm{a}$ is the radius/ major radius and $\mathrm{b}$ is the minor radius.

Early studies on the effects of shape were studied by Faupel and Haris (1957). The researchers presented work on the consequences of adding either elliptical holes or adding circular side holes to highly pressurized cylinders (Faupel and Harris, 1957). The results showed that a correctly positioned circular side hole in a vessel causes maximum stress concentration to develop in the direction of the hoop at the side hole-bore boundary.

Research work by Cole (1969) performed an investigation on the benefits which could be achieved from the application of an 
oblique, or offset the axis for a hole for circular section, or the effects of an elliptical cross-section. The study concluded that there was the possibility to recover a large portion of the capacity to handle the pressure that is 'lost' by the application of a cross-bore elliptical cross-section. To decrease SCFs, the measurements of the outlet ellipse that is shaped when the cross-bore plunges into the main cylinder bore should be in a way that there is equal major to minor axes for maximum stress at the ends (Cole et al., 1976). To fulfill this need, an approximate aspect ratio of 2 was established (Masu, 1997). With the use of finite element analysis gaining popularity, cylinders having optimally shaped elliptical radial cross bore that is, radially positioned or offset circular cross bore were analyzed (Masu, 1997). The results showed that a cylinder having radial elliptical cross bore cylinders develops almost 1.5 times hoop stress than that of circular radial cross bore. This result was later reinforced by Maskulwatudom (2004) where it was reported that centered elliptical cross holes reduce the SCFs considerably but in general lead to higher production costs (Makulsawatudom et al., 2004). The research work went further and reported that the offset circular cross hole which is cheaper to manufacture, reduces the SCF effect however the decease is much lesser than that of an elliptical cross-section crosshole.

Additional study has been reported on the effect of small transverse holes in cylinders having either chamfer or radius on fatigue life of a thick-walled cylinder (Masu and Craggs, 1992). The researchers we surprised that cross-bore cylinders that are plain and having thick ratios $K=1.4$, as well as a thickness ratio of 2.0, have a fatigue strength that is slightly more than similar cylinders with blending characteristics. More research was done on how size and chamfers affect stress distribution in a thick-walled cylinder having cross bore cylinders that are subjected to pressure and have been reported (Kihiu and Masu, 1995). In this work, by varying chamfer angle against a fixed chamfer size and also varying the chamfer length against a fixed chamfer angle, the reaction of stress distribution and SCFs were investigated. The investigation also showed that by introducing chamfers to cross bores in cylinders, stress starts to redistribute. These findings matched a different investigation conducted by Makulsawatudom et al (2004). With further developments in finite element analysis and computer hardware technology, Peters (2003) reevaluated many theories that had been developed earlier. Hence, an investigation on the application of a blend radius to the inside junction of a vessel cross bore vicinity of the hole and stress concentrations established around the hole was done (Peters, 2003). The research gave mixed results from Masu and Craggs (1992) work. It reported that small blend ratios can reduce stress concentration by up to $6 \%$ in certain cases and also may increase by up to $10 \%$. Another study on elastic SCFs for pressurized vessels having a radial circular, offset circular, and elliptical shaped cross holes have been reported
(Makulsawatudom et al., 2004). In this work plain, chamfered, and radius types of connection between the cross hole and main bore were investigated. The study concluded that the introduction of a blend radius or chamfer at the junction diminishes the stress concentration at the main bore but has an effect of introducing higher peak stress elsewhere in the blend or chamfer area. Further investigation of universal SCFs and optimal chamfering in cross bored cylinders have been conducted (Kihiu et al., 2007). It was found that chamfers are more suitable for thick cylinders than thick cylinders.

A study on stress concentration factors in pressure vessels with elliptical cross bores has been done (Adenya and Kihiu, 2010). The researchers observed a decrease of stress concentration factor if an elliptical-shaped cross bore whose major axis was normal to the cylinder axis and was rotated clockwise to the longitudinal plane by 90 degrees. At this position, the minimum stress concentration factor was found to be less than 2 . The investigation developed a conclusion that the maximum stress concentration factors occurred when the major axis of the elliptical cross bore lay in the longitudinal plane. While the minimum SCFS developed when the major axis of the elliptical cross bore lay in the transverse plane.

Stress concentration mitigation techniques have been reported by Nagpal (2012). The paper reported that if you smoothen stress flows lines around the vicinity, stress concentration in the vicinity of singularity can be minimized (Nagpal et al., 2012). The authors proposed some ways of mitigation which include the elimination of material from the vicinity by introducing auxiliary holes, hole shape optimization, and reinforcement of the hole by introducing material. However, the authors noted that shape discontinuities optimization for mitigation of stress concentration may not always be practical because it can be hampered by design constraints, like in case of bolt holes, rivets holes among others.

Finally, analyses have been performed to establish the optimal shape between circular and elliptical plain cross bore at radial and offset positions in closed thick-walled cylinders (Nziu and Masu, 2019b). The paper reported that elliptical shaped cross bore predicted lower hoop stresses at a radial position than circular ones, with a variation of $44.6 \%$ to $66.9 \%$ across the studied ratios. The authors concluded that the optimal location of elliptical cross bores reduces SCF magnitudes by $33 \%$ in comparison to a similar cross bore.

\subsection{Cross bore Location}

Whenever a cross bore is positioned at the centroidal axis of the cylinder is known as a radial cross bore(Nziu and Masu, 2019c). Whereas, offset cross bores refers to laying of the cross bore in any other chord away from the centroidal axis. These terminologies are illustrated in Figures 3 to 4. 


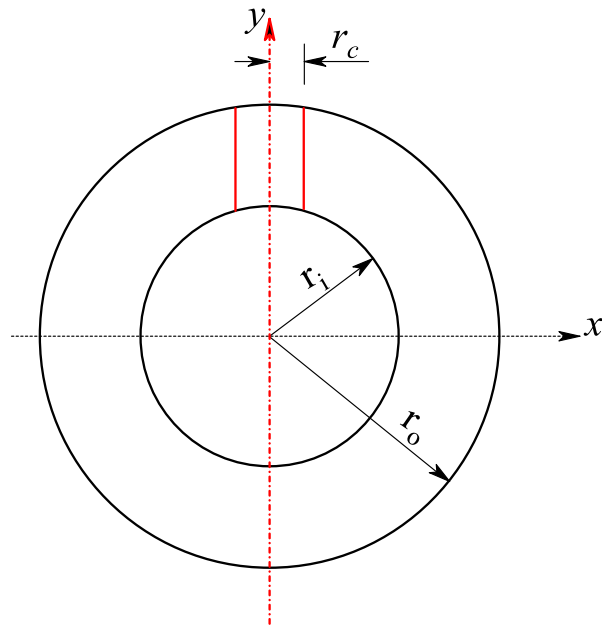

Figure 3. Radial cross bore

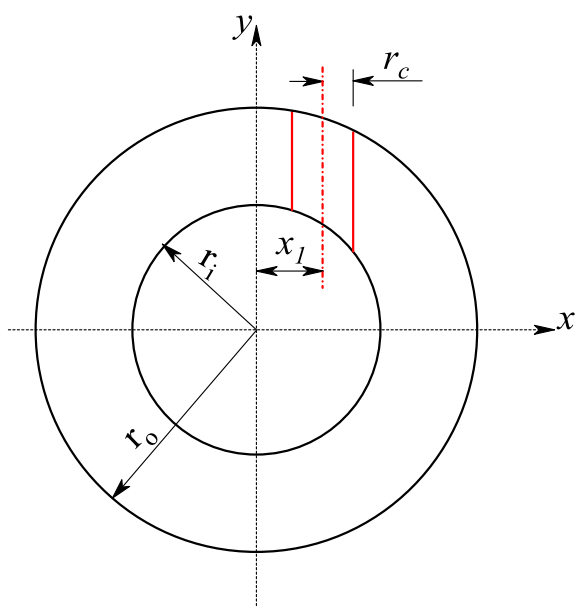

Figure 4. Offset cross bore
Researchers have reported the effect of introducing elliptically or circular shaped side holes to thick-walled cylinders (Faupel and Harris, 1957), and equation 2.5 was the formula developed by Morrison et al (1959), to obtain SCF at a radial position. Identifying the right location of the holes henceforth developed an incredible interest. Therefore, a study on the strength of thick-walled vessels having offset or radial circular shaped cross bores has been reported (Cole et al., 1976). The investigation concluded that offsetting small cross bores from the centerline in a cylinder can increase the fatigue life of a vessel.

Investigations on the comparison of cylinders having either a circular radial shaped cross bore and optimally circular cross bore that is offset from the radial line has been reported (Masu, 1997). This research arose from the need for information on the effect of location on stress distribution and stress concentration. A circular cross bore having a diameter of $1.6 \mathrm{~mm}$ at the radial position that has been offset by $11.2 \mathrm{~mm}$ from the centerline was investigated. The author reported that changing the configuration or offsetting the cross bore is reported to greatly reduce the hoop stress in a plain cross bore cylinder. Therefore, Masu (1997) supported experimentally that by offsetting a cross bore by $11.2 \mathrm{~mm}$ from the radial centerline of the vessel, there was a significant increase in the fatigue life of by up to $170 \%$. Another work on an analysis of circular offset cross bore cylinder has been reported by Masu(1998). Cylinders having thickness ratios of $K=2$ with a diameter of $1.6 \mathrm{~mm}$ and the hole at radial position, $6 \mathrm{~mm}$ offset position, and also $11.2 \mathrm{~mm}$ from the radial centerline were analyzed(Masu, 1998). Hence, by use of finite element analysis, the study concluded that cylinder stress analysis shows that the maximum hoop stresses in the circular radial cross bore cylinders were reaching almost 1.73 times that of the cross-hole cylinder that has been offset by 11.2 mm. Additionally, Makulsawatudom (2004) reported that, offset circular cross hole, which is cheaper to construct than elliptical cross holes, reduces the stress concentration effect however the reduction of stress concentration is lower than that of an elliptical cross hole.

Research on stress concentration at radial cross holes in thick cylinders that are pressurized has been presented (Çömlekçi et al., 2007). The analysis showed that the location of maximum stress does not necessarily occur at the intersection between the bore and main cylinders, as is normally expected to be, but it occurs elsewhere up the cross hole from the intersection.

Another work on location optimization for the opening in a pressure vessel has been reported (Hyder and Asif, 2008). Hence, an analysis of a hole having a diameter of $12 \mathrm{~mm}$ hole and is located at $0.0625,0.125,0.25,0.375$, and 0.5 away from the top of the cylinder height in three different cylinders of 20, 25 and $30 \mathrm{~cm}$, for location optimization was carried out. Results indicated that Von Mises stress is at peak at the radial position which is location 0.5 location and is decreasing from the center and however, the stress increases as the location are changed from 0.125 to 0.0625 from the cylinder due to the end effects. Subsequently, the location of the hole that was optimum was observed to be at the location 0.125 of the cylinder height.

FEA has been conducted on an elastic pressurized thick-walled cylinder to determine the optimal location for an ellipticalshaped cross bore (Nziu and Masu, 2019d). The authors established that the offsetting of an elliptically shaped cross bore increases the magnitude of SCFs and noted that the lowest SCF occurred at the radial position when $K=2.5$ with a magnitude of 1.733. Additionally, the same authors researched to determine the optimal location of a circular cross-bore in thick-walled pressure vessels (Nziu and Masu, 2019e). The research established that the offsetting of circular-shaped cross bores appropriately reduces the magnitude of SCFs. Besides, the optimal location was found to be at 0.9 offset position for a thick-walled cylinder having a thickness ratio of 1.4, and stress concentration factor of 2.312. This stress concentration factor showed a decrease of pressure carrying capacity of the cylinder by $56.7 \%$ as compared to the same plain cylinder without a cross bore.

\section{$5.4 \quad$ Cross bore obliquity}

An oblique hole in a surface is a hole whose axis that is not perpendicular to the plane of the surface (Stanley and Day, 
1990) and therefore the obliquity $(\alpha)$ angle which is the angle between the hole axis and also the plate normal (Stanley and Starr, 2000). Simpler configurations of the normal cross hole in thick-walled cylinders are commonly available and the application of oblique cross bore holes would be needed when unusual constraints are considered which include applications that have restrictive geometries, extraction probes or involving specialized spargers (Nihous et al., 2008).

Therefore, oblique or inclination of cross bores refers to placing cross bores in the longitudinal axis of the cylinder (Nziu and Masu, 2019a) as shown in figure 5.

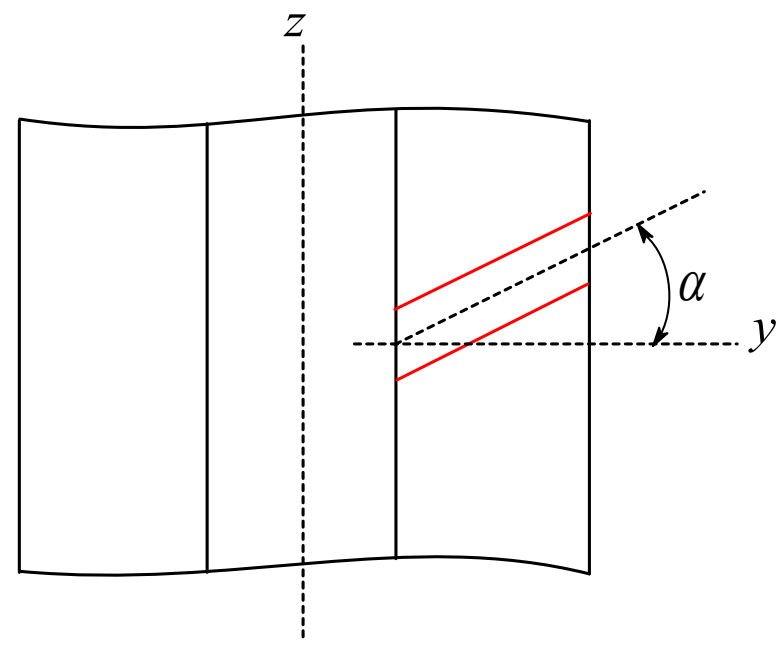

Figure 5. Oblique cross bore

Where

$r_{c}$ is the radius of the cross bore

$r_{i}$ is the internal radius of the main bore

$r_{0}$ is the external radius of the main bore

$x_{1}$ is the offset distance

$\alpha$ is the oblique angle

Research work on stresses of an oblique hole in a thick flat plate that is exposed to constant uniaxial tension has been done (Stanley and Day, 1990). Experimental work was carried out on nominal plate thickness having a hole diameter varying from $1.33,2.0$ to 3.0 , with obliquity angles ranging from $0^{\circ}, 15^{0}, 30^{\circ}$, $45^{\circ}$ to $60^{\circ}$, and the load applied to directions of $0^{\circ}, 30^{\circ}, 60^{\circ}$ and $90^{\circ}$ about the major axis of the surface ellipse. This study showed that the maximum stress index which is the SCF increases will increase with an increase of the obliquity when the load direction is transverse to the major axis of the elliptical intersection of the hole with the plane of the plate. Later, an analytical equation was generated for the elastic SCF for an isolated oblique circular thick plate hole (Stanley and Starr, 2000).

Additionally, a study on elastic SCFs for thick cylindrical vessels that have been pressurized internally, with oblique circular cross holes has been reported (Nihous et al., 2008). In this study a matrix of two wall ratios of $K=2.25$ as well as 4.5 with different five crosshole radius $d$ where crosshole radius/cylinder inner radius of $0.1,0.2,0.3,0.4$, and 0.5 were chosen as illustrative of a range of different geometric configurations that can be traced to literature. Hence, five values of the crosshole angle were selected from the radial case $(\alpha=0)$ to an $\alpha=60^{\circ}$ in increments of $15^{\circ}$. Outcomes of the FEA for two wall ratios show that stress concentration factors rose sharply with the leaning $\alpha$ of the crosshole axis.

A study on the optimization of circular cross bore obliquity has been reported (Nziu, 2018). The author carried out optimization at seven different oblique angles $\alpha$ with an orientation of $15,30,45,60$, and 90 degrees for a studied thickness ratio of $K=1.4$ to $K=3.0$ at the 0.9 offset position. Hence, it has been reported that as you increase the oblique angle from 30 to 90 degrees, SCF progressively increases for all the seven thickness ratios studied. But an increase of oblique angle between 15-30 degrees, the SCF magnitude increased significantly. These results were in line with the earlier studies done by Nihous et al (2008).

\subsection{Thickness ratio}

In general, for a section of thick cylinders, it has been stated that some parameters are important. These parameters include diameter ratio or the cross bore radius ratio, and corner radius ratio (Chaaban and Burns, 1986) which are all thickness ratios. The ratio of the outer and inner radius can be determined using the radii shown in figures 3 and 4. Diameter ratio or wall ratio $K$ is the ratio of external to the internal diameter ratio of the main tube and is shown in eq. 2.1 from Gerdeen (1972). Crosshole ratio $K_{c}$ is a ratio of cross-hole diameter to the internal diameter of a cylinder A Theoretical hoop SCF of 3.70 was initially given then a value of 2.80 for a cylinder of $K=3$. Gerdeen (1972) further gave a comparison of hoop SCF of 1.5, 2.0, 2.5, 3.0, and 4.0 (Gerdeen, 1971). Gerdeen et al (1972) have used a combination of wall ratio and cross-hole ratio to analyze SCFs. Hence, similar materials with different thickness ratios have also been proven to increase the fatigue life of cylinders. Therefore, research work has reported that cross bore positioned optimally gave a fatigue strength of a cylinder that is more than the one having a centered cross bore by about $100 \%$ for a cylinder with $K=1.8$ and also by approximately $170 \%$ for a cylinder with $K=1.4$ (Gerdeen and Smith, 1972). The use of thickness ratios to understand stress distribution has been observed. Masu and Craggs(1992), performed fatigue tests on plain cross bore cylinders with thickness ratios of $K=$ 1.4 as well as $\mathrm{K}=2.0$. The paper gave results showing that for cross bore cylinders that are blended, SCFs are shown to reach unusually high values while those for plain cross bore cylinders the SCFs reached values of 4.1 and 3.1 for $K=2.0$ and 1.4 correspondingly. Therefore, plain cross bores are observed, in the entire length, a decrease in thickness ratio also leads to a decrease in SCF.

Makulsawatudom et al (2004) analyzed the equation. 2.5 explained in section 2.2 and defined $K=b / a$ where $b$ and $a$ are the outer and inner radii correspondingly of the main cylinder. The authors illustrated that for a cylinder of inner radius $b / a=1$ in eq. 2.5 gives an SCF of 2.5. Further, when the 
thickness ratio increases, the SCF also increases. For example a cylinder radius ratio $b / a=2$ has a maximum stress concentration factor of 3.4. The researchers thus went further to analyze five cylinders with different radius ratios of $b / a$ of $1.5,1.75,2,2.25$ and 2.5. Also, two different circular cross holes having different radii were analyzed where radius $R_{c}=0.01 b$ as well as $R_{c}=0.05 b$. The results gave an overall conclusion that the SCF effect was more for the smaller hole, however, a difference of $5 \%$ was observed.

Research on the investigation of SCFs as a function of the ratio of cross bore radius to the cylinder internal radius where $\mathrm{K}=0.01$ varied to 0.07 for a variety of wall ratios of $\mathrm{K}_{\mathrm{s}}=1.5$ to 5 using finite element method has been discussed (Dixon et al., 2002). The paper presented charts detailing the effects of cross bore radius ratios on hoop SCFs in cylinders and blocks. It was concluded that the SCFs in blocks are very similar to those in cylinders with cross bores.

A study on the effects of wall thickness on pressurized elastic thick cylinders has been reported (Nziu and Masu, 2019c). The study aimed to investigate the optimal SCFs as well as the behavior of hoop stress. Cylinders having thickness ratios varying from 3.0 up to 1.4 with cross bore to main bore ratio starting from 0.1 to 1.0 were investigated. With the five circular radial cross bore size ratios analyzed, the smallest cross bore size ratio of 0.1 , generated the minimum hoop stress while the maximum stress occurred with a cross bore size of 1.0. Further, the minimum SCF occurred in the smallest cross bore size ratio of 0.1 at a thickness ratio of 2.25 with a stress concentration factor of approximately 2.836 .

In conclusion, it is clearly shown that geometric design parameters of cross bore size, shape, location, obliquity, and thickness ratios affect stress distribution and SCFs in pressure vessels. Hence, the optimal configuration of these parameters on compound thick compound cylinders becomes essential in design.

\section{SUMMARY DISCUSSION}

This literature survey has reviewed three critical areas that help in understanding the design of pressure vessels. They are Stress Concentration Factors (SCF), measurement of stress distribution, and geometric design parameters affecting stress concentration in high-pressure vessels. Investigation of stress distribution in high-pressure vessels can be measured by experimental, analytical, or numerical techniques. Therefore, numerical modeling using FEA Abaqus software will be used to determine SCFs in thick compound cylinders with a cross bore in this study. Furthermore, from the study on the literature on compound cylinders, it is clearly shown that most investigations and research tend towards the optimization of compound cylinders based on specific parameters that affect the design of compound cylinders like interference. The parameters include shrink radius, diametral interference, material, autofrettage, and other geometries. There is no available information on the effects of cross bores in thick compound cylinders. Additionally, it is also illustrated that geometric design parameters of cross bore size, shape, location, obliquity, and thickness ratios affect stress distribution and
SCFs in pressure vessels.

\section{CONCLUSION STATEMENT}

The optimal configuration of geometric design parameters on compound thick compound cylinders is essential in design. It is, therefore, noted that from the current review that there is no available literature of study using finite element analysis of thick compound cylinders having cross bores. Hence, this study was justified to extensively investigate the effect of geometric design parameters of cross bore size, shape, location, obliquity, and thickness ratio on stress concentration in thick compound cylinders and high-pressure vessels.

\section{ABBREVIATION}

SCF: Stress Concentration Factor; FEA: Finite Element Analysis

\section{ACKNOWLEDGMENT}

This research work is supported by the Vaal University of Technology. The authors wish to thank the Department of Mechanical Engineering at the Vaal University of Technology for facilitating this work.

\section{Availability of data and material}

All cited articles in this review article are available upon request.

\section{Authors' contributions}

All authors jointly contributed to the development of this journal article.

\section{Competing interests}

The authors declare that they have no competing interests.

\section{REFERENCES}

Adenya, C.A. and Kihiu, J.M. (2010), "Stress Concentration Factors in Thick Walled Cylinders With Elliptical CrossBores", Jomo Kenyatta University of Agriculture and Technology. Digital Repository, pp. 181-200.

Bahoum, K., Diany, M. and Mabrouki, M. (2017), "Stress analysis of compound cylinders subjected to thermomechanical loads", Journal of Mechanical Science and Technology, Vol. 31 No. 4, pp. 1805-1811.

Chaaban, A. and Burns, D.J. (1986), "Design of high pressure vessels with radial crossbores", Physica $B+C$, NorthHolland, Vol. 139-140, pp. 766-772.

Cole, B.N. (1969), "Strategy for Cross-Bores in High Pressure Containers", Journal of Mechanical Engineering Science, IMECHE, Vol. 11 No. 2, pp. 151-161.

Cole, B.N., Craggs, G. and Ficenec, I. (1976), "Strength of Cylinders Containing Radial or Offset Cross-Bores.", $J$ Mech Eng Sci, IMECHE, Vol. 18 No. 6, pp. 279-286. 
Çömlekçi, T., Mackenzie, D. and Wood, J. (2007), "Elastic stress concentration at radial crossholes in pressurized thick cylinders", Journal of Strain Analysis for Engineering Design, Vol. 42, pp. 461-468.

Dharmin, P., Khushbu, P. and Chetan, J. (2012), “A Review on Stress Analysis of an Infinite Plate with", International Journal of Scientific and Research Publications, Vol. 2 No. 11, pp. 1-7.

Dixon, R.D., Peters, D.T. and Keltjens, J.G.M. (2002), "Stress Concentration Factors of Cross-Bores in Thick Walled Cylinders and Square Blocks", ASME Pressure Vessels and Piping Conference, Vancouver BC, pp. 31-36.

Faupel, J.H. and Harris, D.B. (1957), "Stress Concentration in Heavy-Walled Cylindrical Pressure Vessels - Effect of Elliptic and Circular Side Holes", Industrial \& Engineering Chemistry, American Chemical Society, Vol. 49 No. 12, pp. 1979-1986.

Fessler, H. and Lewin, B. (1956), "Stress distribution in a tee junction of thick pipes", British Journal of Applied Physics, Vol. 7, p. 76.

Ford, H. and Alexander, J. (1977), Advanced Mechanics of Material, Second Edi., John wiley and sons inc., Canada.

Gerdeen, J. (1971), “Analysis of stress concentrations in thick cylinders with sideholes and crossholes", ASME Pap 71WA/PVP-9 for Meeting, Vol. 94 No. 3, p. 815.

Gerdeen, J.C. and Smith, R.E. (1972), "Experimental determination of stress-concentration factors in thickwalled cylinders with crossholes and sideholes", Experimental Mechanics, Vol. 12 No. 11, pp. 530-536.

Hearn, E. (1997), MECHANICS OF MATERIALS 2, 3rd ed., BUTTERWORTH HEINEMANN.

Hyder, M.J. and Asif, M. (2008), “Optimization of location and size of opening in a pressure vessel cylinder using ANSYS", Engineering Failure Analysis, Vol. 15 No. 1, pp. $1-19$.

Kharat, A. and Kulkarni, V. (2013), "Stress Concentration at Openings in Pressure Vessels-A Review", Int. j. Innov. Res. Sci. Eng. Technol., Vol. 2 No. 3, pp. 670-678.

Kihiu, J.. (2002), Numerical Stress Characterization in Cross Bored Thick Walled Cylinders under Internal Pressure, The University of Nairobi.

Kihiu, J. and Masu, L. (1995), "The effect of chamfer and size on the stress distributions in a thick-walled cylinder with a cross bore under internal pressure", Jomo Kenyatta University of Agriculture and Technology. Digital Repository, Vol. 2 No. February, pp. 73-78.

Kihiu, J.M., Rading, G.O. and Mutuli, S.M. (2007), "Universal SCFs and optimal chamfering in cross-bored cylinders", International Journal of Pressure Vessels and Piping, Vol. 84 No. 6, pp. 396-404.

Kumaresan, M. and Chocklingam. (2018), "Stress Analysis in Compound Cylinder and Autofrettaged Cylinders", International Journal of Engineering Research and Technology, Vol. 7 No. 4.

Majumder, T., Sarkar, S., Mondal, S. and Mandal, D. (2014), "Optimum Design of Three Layer Compound Cylinder",
IOSR Journal of Mechanical and Civil Engineering, Vol. 11, pp. 33-41.

Majzoobi, G.H., Farrahi, G.H., Pipelzadeh, M.K. and Akbari, K. (2004), "Experimental and finite element prediction of bursting pressure in compound cylinders", International Journal of Pressure Vessels and Piping, Vol. 81 No. 12, pp. 889-896.

Majzoobi, G.H. and Ghomi, A. (2006), "Optimization of compound pressure cylinders", Journal of Achievements in Materials and Manufacturing Engineering, Vol. 15.

Makulsawatudom, P., Mackenzie, D. and Hamilton, R. (2004), "Stress concentration at crossholes in thick cylindrical vessels", The Journal of Strain Analysis for Engineering Design, IMECHE, Vol. 39 No. 5, pp. 471-481.

Masu, L.M. (1989), The Effect of Cross Bore Geometry on the Strength of Pressure Vessels, University of Leeds.

Masu, L.M. (1991), "Cross bore geometry effects on the strength of pressure vessels", Proceedings of the International Conference on Mechanics of Solids and Structures, Nayang Technological University, Singapore, pp. 261-272.

Masu, L.M. (1997), "Cross bore configuration and size effects on the stress distribution in thick-walled cylinders", International Journal of Pressure Vessels and Piping, Vol. 72 No. 2, pp. 171-176.

Masu, L.M. (1998), "Numerical analysis of cylinders containing circular offset cross-bores", International Journal of Pressure Vessels and Piping, Vol. 75 No. 3, pp. 191-196.

Masu, L.M. and Craggs, G. (1992), "Fatigue Strength of ThickWalled Cylinders Containing Cross Bores with Blending Features", Proceedings of the Institution of Mechanical Engineers, Part C: Journal of Mechanical Engineering Science, IMECHE, Vol. 206 No. 5, pp. 299-309.

Morrison, J.L.M., Fessler, H., Lewin, B.H., Crossland, B., Parry, J.S.C., Faupel, J.H., Harris, D.B., et al. (1959), "Lake, G. F., Proc. Inst. Conf. Fatigue of Metals, Inst. Mech. Engrs., London, 743 (1956).”, J. Ind. Chem., Vol. 7.

Nagpal, S., Jain, N. and Sanyal, S. (2012), "Stress Concentration and Its Mitigation Techniques in Flat Plate with Singularities - A Critical Review", Engineering Journal, Vol. 16, pp. 1-16.

Nihous, G.C., Kinoshita, C.K. and Masutani, S.M. (2008), "Stress concentration factors for oblique holes in pressurized thick-walled cylinders", Journal of Pressure Vessel Technology, Transactions of the ASME, Vol. 130 No. 2, pp. 0212021-0212027.

Nziu, P.K. (2018), Optimal Geometric Configuration of a Cross Bore in High Pressure Vessels. In Doctorate Thesis, Vaal University of Technology.

Nziu, P.K. and Masu, L.M. (2019a), "Cross bore geometry configuration effects on stress concentration in highpressure vessels: a review", International Journal of Mechanical and Materials Engineering, Vol. 14 No. 1, p. 6.

Nziu, P.K. and Masu, L.M. (2019b), “Configuration of optimal 
cross bore shape in elastic pressurized high pressure vessels", International Journal of Mechanical and Production Engineering Research and Development, Vol. 9 No. 5, pp. 197-210.

Nziu, P.K. and Masu, L.M. (2019c), "Cross bore size and wall thickness effects on elastic pressurised thick cylinders", International Journal of Mechanical and Materials Engineering, Vol. 14 No. 1, p. 4.

Nziu, P.K. and Masu, L.M. (2019d), “An Optimal Location of Elliptical Cross Bore in Elastic Pressurized Thick Cylinders", International Journal of Mechanical and Production Engineering Research and Development, Vol. 9, pp. 287-298.

Nziu, P.K. and Masu, L.M. (2019e), "Offsetting of Circular Cross Bore Effects on Elastic Pressurized Thick Cylinders", International Journal of Mechanical and Production Engineering Research and Development, Vol. 9, pp. 71-82.

Patil, A. (2013), "Finite element analysis of optimized compound cylinder", Journal of Mechanical Engineering Research, Vol. 5 No. 5, pp. 90-96.

Peters, D. (2003), Effect of Blend Radius on Stress Concentration Factor of Crossbored Holes in Thick Walled Pressure Vessels, American Society of Mechanical Engineers, Pressure Vessels and Piping Division (Publication) PVP, Vol. 455.

Qadir, M. and Redekop, D. (2009), "SCF analysis of a pressurized vessel-nozzle intersection with wall thinning damage", International Journal of Pressure Vessels and Piping, Vol. 86 No. 8, pp. 541-549.

Reghunath, R. and Sammon, K. (2014), "Analysis of Internally Pressurised Thick Walled Cylinders", Journal of Basic and Applied Engineering Research, Vol. 1 No. 2, pp. 8389.

Stanley, P. and Day, B. V. (1990), "Photoelastic investigation of stresses at an oblique hole in a thick flat plate under uniform uniaxial tension", The Journal of Strain Analysis for Engineering Design, IMECHE, Vol. 25 No. 3, pp. 157-175.

Stanley, P. and Starr, A.G. (2000), "Stress concentrations at an oblique hole in a thick plate", The Journal of Strain Analysis for Engineering Design, IMECHE, Vol. 35 No. 2, pp. 143-147.

Zhang, Q., Wang, Z.W., Tang, C.Y., Hu, D.P., Liu, P.Q. and Xia, L.Z. (2012), "Analytical solution of the thermomechanical stresses in a multilayered composite pressure vessel considering the influence of the closed ends", International Journal of Pressure Vessels and Piping, Vol. 98, pp. 102-110. 